\title{
Ortopedia do corpo, eficiência dos gestos, ciência para o esporte: modelos pedagógicos na Educação Física brasileira e na formação de seus professores
}

\section{Body Orthopedics, gesture efficiency, sports oriented science: pedagogical models at Brazilian Physical Education and in the training of its teachers}

\author{
Meily Assbú Linhales* \\ Giovanna Camila da Silva* \\ Fernanda Cristina dos Santos*
}

\begin{abstract}
RESUMO
Este artigo analisou a constituição de três modelos pedagógicos na Educação Física brasileira, entre as décadas finais do século XIX e os anos de 1980, colocando em contraste a ortopedia do corpo, a eficiência dos gestos e a ciencia para o esporte como formas disciplinares distintas de produção de sentidos para a área. Foram priorizadas fontes impressas, especialmente aquelas que abordam métodos e orientações pedagógicas, além de documentos organizadores de políticas. Os indícios perscrutados e o diálogo com a historiografia do campo permitiram dar operatividade à noção de modelo pedagógico estabelecida por Marta Carvalho (2011), e lançar um olhar atento aos léxicos contribuiu na composição de cada um deles, pois algumas palavras-chave foram pistas importantes na compreensão dos processos históricos investigados. A análise implicou reconhecer nas
\end{abstract}

${ }^{*}$ Universidade Federal de Minas Gerais, Belo Horizonte, Minas Gerais, Brasil. E-mail: meily_linhales@yahoo.com.br - https://orcid.org/0000-0003-2762-4916 E-mail: giovannaufmg@ yahoo.com.br - https://orcid.org/0000-0002-5705-0573 E-mail: santos.fernandacs@gmail.com https://orcid.org/0000-0002-8068-6027 
representações sobre a Educação Física as interlocuções com outros países, dando a ver múltiplas práticas de circulação e apropriação presentes nas maneiras de educar o corpo, na escola e fora dela.

Palavras-chave: História da Educação Física. Modelos Pedagógicos. Ensino de Educação Física. Formação de Professores. Educação do Corpo.

\begin{abstract}
This paper has analyzed the constitution of three pedagogical models at Brazilian Physical Education, from the latter decades of the 19th century to the 1980s, putting into contrast the body orthopedics, gesture efficiency, and sports-oriented science as distinct disciplinary ways of producing meaning for Physical Education. We prioritized written sources, especially those that address pedagogical methods and guidelines, besides policy organizing documents. The material analyzed and the dialog with field historiography allowed us to put into work the notion of pedagogical model settled by Marta Carvalho (2011), and a watchful eye to the lexicon has contributed to the composition of each one of them, for a few keywords were significant clues in the comprehension of the historical processes investigated. The analysis required to identify in the representation on Physical Education the interlocutions with other countries, evincing multiple practices of circulation and appropriation present in educating the body, at school and outside it.
\end{abstract}

Keywords: History of Physical Education. Pedagogical Models. Physical Education Teaching. Teacher Training. Body Education.

\title{
Introdução
}

Os estudos relativos à História da Educação Física brasileira têm nos permitido elucidar algumas proposições pedagógicas que, especialmente no século $\mathrm{XX}$, construíram ordenamentos socioculturais para a formação de professores, a sistematização de métodos de ensino e o desenvolvimento de práticas escolares. Partimos do pressuposto de que a escolarização da Educação Física e a sua afirmação como disciplina escolar constituíram-se processualmente e se integraram, muitas vezes, às mudanças realizadas também no campo educacional, em seu constante diálogo com valores, normas e expectativas de cada tempo. Essa tessitura chamada Educação Física igualmente se produziu por inventivas apropriações de contribuições estrangeiras que circularam no país pela ação de diferentes sujeitos, artefatos ou práticas e pela acomodação 
de ideias e interesses atinentes aos dispositivos pedagógicos, médico-sanitários, militares, religiosos ou científicos aí representados.

Desse modo, o campo pedagógico da Educação Física tem sido por nós abordado como um amálgama, uma fabricação cultural, o que fez despertar a pertinência da noção de modelo pedagógico. Tanto na constituição da disciplina escolar Educação Física, quanto na consolidação dos projetos para a formação de professores, estiveram incluídos preceitos modelares que, ao selecionar e indicar saberes e práticas, validaram maneiras de ensinar, autorizaram diferentes moldes e/ou identidades para a Educação Física. A operação realizada apoia-se nos argumentos de Marta Maria Chagas de Carvalho (2011, p. 188), quando adverte que "falar em 'modelo' como ferramenta de análise no campo da pesquisa historiográfica implica trabalhar com sistemas de relações, testando a pertinência descritiva e analítica destes sistemas, no diálogo com as fontes documentais" (grifos da autora). Nesse exercício de reunir e inquirir as fontes, nossas análises não se orientaram por "modelos construídos aprioristicamente" (CARVALHO, 2011, p. 188), pois os mesmos foram identificados no decurso das pesquisas, a partir dos indícios suscitados pelos documentos, onde foram reconhecidos os sistemas de relações e as redes que os constituíram, em diferentes momentos históricos. Um olhar atento aos diferentes léxicos contribuiu no delineamento de cada um dos modelos, pois algumas palavras-chave, os usos e também os desusos a elas atribuídos, foram pistas importantes na compreensão dos processos históricos analisados.

Neste artigo pretendemos elucidar a ortopedia do corpo, a eficiência dos gestos e a ciência para o esporte como modelos pedagógicos produzidos (e produtores) na/da Educação Física brasileira, bem como os dispositivos disciplinares que lhes dão sustentação. Tal operação apresentou-se como decorrência de nossas atividades coletivas de pesquisa, em uma temporalidade demarcada entre as últimas décadas do século XIX até os anos de 1980. A cada etapa, novos temas e novos objetos de investigação confirmavam as contribuições da História da Educação para o refinamento necessário à História da Educação Física e da formação de seus professores ${ }^{1}$.

1 Desde 2012, a temática dos modelos pedagógicos está presente em nosso grupo que reúne pesquisadores e alunos de doutorado, mestrado e iniciação científica. Como uma linha de investigação, constitui parte das atividades de pesquisa do Centro de Memória da Educação Física, do Esporte e do Lazer (Cemef/UFMG), sediado na Escola de Educação Física, Fisioterapia e Terapia Ocupacional, e integra o GEPHE - Centro de Pesquisa em História da Educação, sediado na Faculdade de Educação da UFMG. Nesse percurso os estudos receberam fomento do Conselho Nacional de Desenvolvimento Científico e Tecnológico (CNPq) - Chamada Pública Universal 14/2011 e Chamada MCTI/CNPq/MEC CAPES 43/2013 e da Fundação de Amparo à Pesquisa do Estado de Minas Gerais (FAPEMIG) - Edital Universal - 01/2013 e 01/2017. 
Mapear essa trama e suas singularidades não implicou desconectá-la do que atravessava fronteiras ou das propostas acolhidas e muitas vezes buscadas em outros países. Ao contrário, exigiu reconhecer que, em diferentes tempos e lugares, as maneiras de educar o corpo, na escola e fora dela, obedeceram aos constantes exercícios de "ler, ver, ouvir e contar... o outro" (LOPES, 1996, p. 35), próprios de nossa condição humana e de nossa experiência na cultura. Próprios também à escrita da História. Essa expressão, de Eliane Marta Teixeira Lopes (1996), refere-se ao trabalho com as fontes históricas, ofício primeiro do historiador:

"A disposição para se fazer História ou a disposição para se ler o mundo como um dispositivo historiador, [...]. Mesmo que tenhamos medo de enfrentar aqueles e aquelas que, em algum momento, se tornam fantasmas, de nós mesmos ou da sociedade. [...]. O tempo do nosso pensamento é o tempo da historiografia, da escrita da História. (LOPES, 1996, p. 35).

\section{Da ortopedia do corpo}

Com a denominação de gymnastica, por vezes também associada aos "exercícios físicos" e às "evoluções militares", algumas práticas para uma educação corporal foram enraizadas na escola brasileira, entre o último quartel do século XIX e as primeiras décadas do século XX. Guardadas as diferenças regionais, podemos considerar que a gradativa afirmação dos exercícios ginásticos como parte constitutiva dos tempos e espaços escolares acompanhou uma expectativa de renovação e modernização do próprio ensino escolar que, entre outros aspectos, afirmava "a tríade spenceriana da educação intellectual, moral e physica" (VAGO, 2010, p. 51). Na ciência da época foram buscados os parâmetros para justificar escolhas e ações pedagógicas, não sendo casual o diálogo estabelecido entre médicos e educadores visando autorizar prescrições de exercícios corporais e outras práticas que adentravam as escolas primárias e secundárias. Nessa perspectiva de análise, buscamos mapear elementos de uma tessitura escolar e não de uma Educação Física produzida como algo exterior à escola.

A partir das contribuições de Carvalho $(1997,2003)$ compreendemos a escola moderna como uma instituição disciplinar e tal argumento encontra significativos lastros nas práticas discursivas e institucionais que, no Brasil, 
apostaram nos processos de escolarização da sociedade como condição de afirmação e consolidação da vida republicana instituída a partir de 1889. Aquele foi também um tempo de importantes mudanças no plano cultural, pois uma nova ordem, capaz de alavancar o progresso, ainda que bastante disperso, precisaria ganhar visibilidade. Em diferentes cidades brasileiras, a escola participou desse novo desenho nacional: "na monumentalidade dos seus edifícios, o Grupo Escolar será essa instituição-signo, com suas classes constituídas segundo o modelo de ensino seriado em que são reunidos alunos de um mesmo grau de adiantamento" (CARVALHO, 2003, p. 336).

Neste contexto, a educação de um cidadão republicano, urbano e moderno, passaria também pela educação de seu corpo. A escolarização da gymnastica foi defendida e justificada a partir da prevalência de um discurso ortopédico que, primando pela correção, apostava na capacidade retificadora e no potencial preventivo da educação escolar frente a uma infinidade de deformações (corporais e não corporais) atribuídas aos brasileiros. De acordo com Tarcísio Vago (2010), em um primeiro momento as justificativas para a inclusão da ginástica na escola primária se orientavam pela intenção de uma correção dos corpos que, presentes nos primeiros Grupos Escolares da cidade de Belo Horizonte, eram considerados "empenados", "débeis" e "raquíticos" (VAGO, 2010, p. 51-54). Como uma outra face dessa mesma construção cultural, a inclusão regular dos exercícios ginásticos nas instituições escolares também modificava a própria escola em suas rotinas, agregando a ela novos sujeitos e práticas. Como argumentam Diogo Puchta e Marcus Aurélio Taborda de Oliveira (2019, p. 5), "ao ser escolarizada, a ginástica parece ter influenciado a definição e concessão dos intervalos, em função de preocupações sobretudo higiênicas, interferindo, consequentemente, na composição dos horários da instituição escolar como um todo".

Nas linhas e entrelinhas presentes nas prescrições e nas práticas, há um forte e recorrente apelo à ortopedia ("orthos" [reto] e "paidion" [criança]) que afirmava a representação de que a escola, e dentro dela a ginástica, cumpririam um papel de (re)educação da natureza dos corpos, especialmente os das crianças, degenerados por aquilo que era considerado nocivo na vida social. Em estudo sobre a cidade do Rio de Janeiro nas últimas décadas do século XIX, Anna Luiza Ferreira Romão (2016) argumenta que a presença de uma ginástica racionalizada e metodizada já se afirmava como prática legítima, na medida em que "desenvolvia o físico e, de forma complementar, a formação intelectual e moral. Protagonista da busca por corpos eretos, robustos, saudáveis e disciplinados, ela entrava em acordo com a sociedade em voga: ordenada, moralizadora, moderna e civilizada" (ROMÃO, 2016, p. 151). 
É nessa perspectiva analítica que tomamos a ortopedia como uma "metáfora da disciplina" (CARVALHO, 1997), como antes de nós já o fizeram Tarcísio Vago (2010) e Omar Schneider (2004). A partir dessa ênfase disciplinar, identificamos que essa modelagem ortopédica se apresentava de modo recorrente nos processos de justificação relativos à inclusão da ginástica nas escolas primárias e secundárias como uma aposta republicana. O estudo de Vago (2010) confirma esse acolhimento ao primado da correção dos corpos nas décadas iniciais do século XX:

No relato da diretora Ignacia F. Guimarães, do "Grupo Escolar Henrique Diniz", da Capital, encontra-se uma tradução contundente desse primado. Ao final do ano de 1915, analisando a prática de ginástica em seu grupo escolar, ela escreveu: "os resultados desses exercicios foram excellentes. Alumnos que, a principio, apresentavam posição incorreta e andar desgracioso, corrigiram-se em pouco tempo" (VAGO, 2010, p. 35-36)

Para captar tais recorrências nas fontes, alguns impressos têm sido balizares: planos de ensino, discursos proferidos em congressos de Instrução Pública, de Higiene e/ou de Eugenia, teses médicas, pronunciamentos e pareceres parlamentares, manuais e compêndios em circulação ${ }^{2}$. Tomando a correção dos corpos como um modelo pedagógico, consideramos relevante destacar que a formação de mestres para as escolas era ainda insipiente e o autodidatismo apresentava-se como o caminho comum. As práticas escolares eram orientadas por manuais e compêndios nos quais as lições se apresentavam quase sempre como pré-estabelecidas, cabendo aos mestres a tarefa de reproduzi-las. Publicado em Portugal pelo mestre Paulo Lauret, em 1881, o "Manual Theorico-Pratico de Gymnastica para uso dos lycéus, collegios, escolas municipaes e primarias", teve ampla circulação no Brasil. De acordo com o autor, a escrita foi inspirada em produções do seu país e em "outros livros francezes e allemães sobre a arte" (LAURET, 1881, p. 8). Nessa obra, os princípios da ortopedia se expressam nas partes que a compõem: "Gymnastica, como meio regenerador", "Gymnastica, como meio preventivo" e "Gymnastica, como meio curativo (ou médico)" (LAURET, 1881, p. 79-80).

2 Neste artigo, serão priorizadas as fontes impressas, especialmente aquelas que, tendo os professores como leitores visados, abordam métodos e orientações pedagógicas: manuais, revistas, livros, cartilhas etc. Também os documentos organizadores de políticas receberam nossa atenção. 
Como a publicação de Paulo Lauret, havia uma gama de manuais em circulação no país (PUCHTA, 2015), sendo os mesmos apropriados, quando não copiados literalmente, de produções europeias que difundiam as sistematizações elaboradas por mestres das denominadas escolas sueca, alemã, dinamarquesa e francesa de ginástica, entre outras. Tais manuais podem ser interpretados como "bons moldes", por agregarem a possibilidade de serem imitados e reproduzidos e, mesmo com alguns ajustes, tenderem a uma homogeneização das práticas que por esse caminho, se tornavam exemplares (CARVALHO, 2011, p.188).

Parece-nos possível afirmar que a presença dos exercícios físicos nas escolas, tendo a ginástica como prática principal, implicou uma propagação dessas "maneiras de ensinar", uniformizadas, por meio de uma constante recriação dos moldes europeus - sendo os manuais e compêndios a sua melhor expressão (PUCHTA; TABORDA DE OLIVEIRA, 2019; AVELAR, 2018; LINHALES; FONSECA, 2016). Entre os termos-chave que participavam de um léxico recorrente, estavam o corpo ereto, a disciplina, os movimentos sincronizados, o apelo científico aos ditames da anatomia e da fisiologia, a relação entre a pedagogia e a "therapeutica" . Assim afirmou o Dr. Schreber, no prefácio de seu manual intitulado Gymnastica Médica, Domestica e Hygienica, que foi adotado em algumas escolas no Brasil:

Os processos cujas práticas aconselhamos no presente livro, constituem um systema em tudo conforme com as leis da natureza, por meio do qual a vida civilisada, nos seus progressos dia a dia mais elevados e sublimes, póde ser collocada e mantida em completo accôrdo com as leis fundamentaes do organismo, por meio do qual o desenvolvimento do nosso corpo pode ser beneficiado e defendido das innumeras imperfeições e enfermidades por que póde ser affectado e, finalmente, por meio do qual os vôos do nosso espirito podem ser estabelecidos em bases definidas, que na verdade lhe são indispensáveis (SCHEREBER, [18--?], p. 4).

3 Sobre o apelo à cientificidade, vale ressaltar que o mesmo sempre esteve presente nos processos de afirmação da Educação Física (e também da escola moderna). Em nossos estudos, não foi incomum encontrar, na produção de um modelo pedagógico, mecanismos discursivos de identificação dos limites científicos relativos ao modelo anterior. Sobre as relações entre Educação Física e Ciência, veja-se Quitzau; Moraes e Silva, 2020. Sobre as relações entre a educação escolar e a medicina na constituição da pedagogia como "educação do corpo", ver Gondra (2004). 
Essa aposta na correção disciplinada do corpo e na condução de seu desenvolvimento de modo racional e progressivo ganharia diferentes nuanças, conforme os manuais eram traduzidos, escritos e reescritos e sua circulação se espraiava por diferentes regiões no Brasil como produções locais. Vale ponderar que essa modelagem escolar atribuída à ginástica concorria com outras "maneiras de fazer", já que nos clubes e ginásios (não escolares) as acrobacias, os espetáculos e o entretenimento se sobrepunham à ortopedia dos corpos, como identificou Romão (2016) no seu estudo sobre o Rio de Janeiro. Vestígios sempre atualizados de uma tensão cultural entre a escola e outras instituições produtoras de uma cultura gímnica para o corpo, como o circo, o teatro ou o funambulismo.

Os manuais de ginástica e suas lições foram um molde adotado no Brasil até os anos de 1930 ou 1940. Entretanto, pode-se notar que em meados da década de 1920, já começava a acontecer uma sutil transformação nos discursos e práticas relativas à educação do corpo. As orientações fortemente baseadas na ortopedia, prescritas nos manuais e lições, pareciam tornar-se pouco exitosas e também insuficientes. Isto porque novas mudanças consideradas necessárias passam a ser demandadas no campo educacional, especialmente para a escola primária.

Em 1928, ao regressar de viagem aos Estados Unidos, Anísio Teixeira critica as concepções pedagógicas vigentes no Brasil, dando prioridade à crítica da psicologia das faculdades mentais. Qualifica os procedimentos escolares referenciados por essa teoria como uma espécie de "treino do ginasta para adquirir certa e determinada habilidade", opondo a eles as concepções de Dewey que aboliam a "distinção arbitrária entre atividade e capacidade e seus respectivos objetos" (CARVALHO, 2011, p.196).

Nesse clima de transição, os mestres de ginástica autodidatas são representados como atrasados e a formação de professores especializados tornava-se uma reivindicação importante, embora o ensino baseado nos manuais ainda permanecesse por algum tempo. Diante do novo discurso que se anunciava, a educação baseada em "bons moldes" começava a ser criticada e, não por acaso, comparada a um "treino de ginastas". 


\section{Da eficiência dos gestos}

A renovação pedagógica operada na década de 1920 potencializou a produção de outros contornos para a Educação Física. A busca por uma escola mais ativa, a expectativa de aproximação com o universo infantil e o anseio de educar para a vida em sociedade promoveram a escolarização de diferentes saberes para a matéria, a ampliação dos seus objetivos e distintas demandas para a formação de seu professorado. A remodelação dos exercícios físicos permitiu que a denominação "Educação Física" fosse cada vez mais mobilizada para designar o componente escolar responsável pela educação corporal. Outros passam a ser os sentidos de educar o corpo da criança, buscando não apenas o aperfeiçoamento físico, como também a estreita relação com a incorporação de códigos sociais referenciados nos novos ritmos urbano e industrial. São elementos que anunciam deslocamentos nas "maneiras de fazer" e confirmam a operatividade da noção de modelo pedagógico por possibilitarem constatar uma nova "metáfora para a disciplina", como atenta Carvalho (1997, 2011). Assim, as mudanças educacionais anunciadas na transição dos anos de 1920 para 1930 inauguram a sistematização de proposições para a formação dos professores de Educação Física e permitem identificar a emergência de um segundo modelo, o da eficiência dos gestos. Vale aqui considerar que a expressão "eficiência dos gestos" foi adotada pela primeira vez por Tarcísio Mauro Vago, em sua tese de doutoramento. Por vezes, o autor adotou também a expressão "eficiência dos corpos" (VAGO, 2010).

Antes da configuração das escolas superiores, as inspetorias de Educação Física ocuparam lugar importante na implementação de políticas educacionais. Foram elas responsáveis pela realização de cursos intensivos, pela publicação de materiais que subsidiassem o trabalho dos professores e ainda pela constituição e fiscalização de ações relativas à escolarização da disciplina. Renato Eloy de Andrade, o inspetor de Educação Física de Minas Gerais, afirmava em 1928 que “o candidato ao ensino da educação physica, profissão relativamente nova, terá que se orientar de maneira muito diversa da até então seguida". E explicitava em que consistia a distinguida orientação para a qualificação docente:

Em logar de apprender exclusivamente jogos e exercicios e então considerarse apto para ensinar e guiar a creança no desenvolvimento do seu organismo, deve, principalmente, fazer um estudo mais ou menos detido da anatomia, physiologia, hygiene, psychologia e, sobretudo, da evolução da raça, que lhe fará comprehender o verdadeiro significado do progresso physico, mental e moral do genus homo (JORNAL MINAS GERAES, 1928, p. 9). 
Novas definições para a formação do professorado são mais bem interpretadas se localizadas no contexto de mudanças e transformações demandadas para todo o ensino escolar, em que os pressupostos da Escola Nova apresentavam fina sintonia com um projeto de uma nova sociedade. Diana Vidal e André Paulilo (2003, p. 375) afirmam que esse movimento educacional nas décadas de 1920 e 1930 apoiava-se "no progresso das ciências biológicas e psicológicas, nas atribuições sociais da escola, no industrialismo, na atividade infantil e no trabalho em solidariedade". Não sem conflitos e disputas, a presença de elementos pedagógicos da Escola Nova informando a Educação Física estende-se para as décadas de 1940, 1950 e 1960 como ênfases produtoras de sentido para a dinâmica escolar e para a formação de professores É possível citar a aproximação com as experiências dos alunos, a necessidade de expressão dos instintos infantis, o reconhecimento das brincadeiras, dos jogos e dos esportes como práticas potentes para a aprendizagem de códigos sociais.

Como secretário do interior, Francisco Campos afirmou que uma reforma do ensino primário não poderia prescindir de um professorado competente para operar a reconfiguração da instrução em Minas Gerais. Não era de boa razão "que o Estado se proponha ministrar uma instrucção primaria graduada e complexa, sem antes cuidar na formação de um professorado sufficientemente apto a exercer com efficiencia o graduado magisterio que se lhe incumbe" (JORNAL MINAS GERAES, 1926, p. 4). Formar-se como professor exigiria mais do que aprender a reproduzir boas receitas e a capacidade de organizar as atividades docentes a partir de um alargado repositório de informações passava a ser fundamental nos processos de formação.

Os conhecimentos da psicologia e da sociologia adentram o campo da Educação Física, indicando que a educação do corpo poderia e deveria constituirse como parte indissociável de uma educação integral, de uma educação para a vida. A Educação Física (não mais ginástica) vai gradativamente ganhando complexidade como um componente escolar. Passam a ser reivindicados tempos e espaços pedagógicos próprios, diversificam-se seus conteúdos jogos, ginástica historiada, danças, calistenia e esportes passam a modelar o ensino escolar -, ganha visibilidade a preocupação com os processos de ensino, incorporam-se múltiplos saberes à formação docente. Essa nova configuração, como anuncia Carvalho (1997, p. 301), encontrava-se ancorada nos preceitos pedagógicos que anunciavam "uma aposta otimista na natureza infantil e na educabilidade da criança".

A metáfora da "disciplina como eficiência" (CARVALHO, 1997; VAGO, 2010; SCHNEIDER, 2004), permite ver a potência da escolarização dos jogos e dos esportes pelas relações estreitas que poderiam estabelecer com os ritmos fabris e que possibilitaria formas singulares de intervenções pedagógicas. Ao 
operar com a eficiência dos gestos, visibilizada na eficácia do funcionamento fisiológico dos corpos, no aperfeiçoamento da unidade psicofísica, no desenvolvimento do senso de responsabilidade, da iniciativa, do entusiasmo, do trabalho em equipe, do alcance de objetivos e da conquista de resultados, a Educação Física promoveria códigos sociais de referência para as dinâmicas do mundo do trabalho, enfatizando preceitos culturais e prescrições para a formação do caráter. Junto com as contribuições europeias já adotadas no país, o intercâmbio entre educadores brasileiros e estadunidenses apresentou outros códigos culturais como orientações pedagógicas: a atenção aos centros de interesse, a organização de práticas educativas por meio de experimentações, o ensino como laboratório psicopedagógico, a recreação, entre outros (SILVA, 2017; LINHALES, 2015) No âmbito da Associação Brasileira de Educação alguns educadores fizeram críticas ao Método Francês adotado oficialmente para as escolas primárias desde o ano de 1929, publicadas na Revista Schola, em março de 1930, por meio do artigo "A Educação Física no Brasil" (LINHALES, 2015). As críticas e o enfrentamento ao referido método se estenderam pelas décadas seguintes baseados em questionamentos sobre sua vinculação militar, sua adequação ao povo brasileiro, sua estrutura de trabalho, sua prescrição tardia dos esportes.

Sob o efeito do final da segunda grande guerra, no clima de reconstrução das nações, uma ênfase na função biopsicossocial da Educação Física se estabelece no Brasil, em consonância com a propagação do ideário desenvolvimentista e com a criação de instituições engajadas na busca de soluções para os problemas da educação (XAVIER, 2007). A exigência de métodos e técnicas de ensino para o exercício docente permitiu a produção de novos marcos nas políticas educacionais e, no campo da Educação Física, a ampliação de departamentos estaduais, de escolas superiores, de associações de professores, além de um redirecionamento das iniciativas da Divisão de Educação Física, do Ministério da Educação e Saúde, criada em 1937.

Por intermédio desses diferentes lugares, novos intercâmbios internacionais trouxeram ao Brasil a Moderna Ginástica Sueca que, estruturada por diversos sujeitos em variadas maneiras de fazer, se distanciava de uma concepção "rígida", "anatômica" e "monótona", considerada própria ao tradicional sistema de ginástica. Como afirmam Anderson Baía e Andrea Moreno (2020, p. 701), "uma nova roupagem foi necessária para a ginástica sueca continuar em cena na disputa por um lugar na educação dos corpos". Conforme Alfredo Faria Júnior (1974, p. 131), ainda foram significativos, na circulação de saberes para a qualificação do "moderno professorado especializado", o Método Natural Austríaco e a Educação Física Desportiva Generalizada. Na obra "Introdução à didática de Educação Física", o autor argumenta: 
Inúmeros métodos de Educação Física foram empregados no Brasil até que ficasse definida a tendência atual de emprego de métodos que busquem um desenvolvimento integral e não apenas o físico; que melhor se apliquem à massa, embora sem abandonar os infradotados e os superdotados; e que se utilizem de formas de trabalho caracteristicamente naturais e globais (FARIA JÚNIOR, 1974, p. 131).

Conceber os alunos como "massa" e, ao mesmo tempo, construir estratégias para um ensino integral capaz de adaptar também os "infradotados" e "superdotados", expressa valores em circulação, bem como os fins que orientavam os argumentos biopsicossociais. Estas, entre outras propostas para a organização do ensino, estiveram presentes na formação de professores e os processos de atualização docente adotaram novas estratégias de difusão e visibilidade em diferentes estados brasileiros, por meio de cursos de aperfeiçoamento e intercâmbios nacionais e internacionais, como confirmam os estudos de Ana Paula Fonseca (2020), Luciana Cunha (2017) e Cássia Lima (2012).

As balizas desse segundo modelo pedagógico instituíram ainda o espraiamento de um projeto educativo para outros espaços da cidade. As noções de recreação e de lazer destacavam-se pelo seu potencial pedagógico e reforçavam a complexa combinação entre liberdade e eficiência social (LOURENÇO FILHO apud CARVALHO, 1997). De modo a articular energia, interesse, eficiência e moderação, as intervenções da Educação Física atentavam para uma sutil condução da liberdade das crianças, por meio de "comportamentos adaptados a funções" (CARVALHO, 1997, p. 308). Ajuste forjado por uma nova compreensão dos corpos infantis que, além de um porte endireitado, deveriam incorporar as novas sensibilidades e os novos ritmos da sociedade da técnica e do maquinismo.

A criação de playgrounds e praças de jogos e de esportes, desde a década de 1930, apresentou-se como "complemento indispensável da ação e orientação educacional da escola" (JORNAL MINAS-GERAIS, 1931, p. 8), conforme argumentou o Inspetor de Educação Física de Minas Gerais ${ }^{4}$. A aposta na criação de espaços cada vez mais esportivos e que promovessem a ampliação de práticas formativas se estendeu nas décadas seguintes. Auguste Listello, educador francês

4 A temática das praças de jogos e dos parques infantis é objeto de pesquisa de autores que investigaram a constituição de tais espaços e sua relação com a natureza, a Educação Física e a educação do corpo. No diálogo com o campo educacional nos anos de 1930 e 1940, destacamos os trabalhos de André Dalben e Kátia Danailoff (2009) sobre São Paulo, e de Giovanna Silva (2019) sobre experiências em Minas Gerais, no Rio Grande do Sul e no Rio de Janeiro. 
que fez circular a Educação Física Desportiva Generalizada no Brasil, orientava os professores para a organização do ensino de Educação Física tanto para as escolas quanto para os clubes de lazer e recreação (CUNHA, 2017). Dizia ele que "hoje em dia não se pode mais pensar somente no que os alunos fazem durante as horas obrigatórias de Educação Física, mas também pensar, e com muito mais interesse, no que farão após o horário escolar" (LISTELLO, 1973, p. 25 apud CUNHA, 2017, p. 213).

O signo da eficiência marcaria o corpo e a educação dos gestos, dentro e fora das escolas, como lugares de necessárias regulagens, orientadas pelas contribuições da psicologia e da sociologia educacionais. A insistente qualificação docente foi ainda marcada pela crença de que um repertório de saberes, métodos e práticas intercambiados e considerados modernos, promoveria maior contribuição da Educação Física ao desenvolvimento social, cultural e econômico do país. Todavia, a partir da década de 1960, a eficiência assume novos contornos, agregando signos mais esportivos e científicos.

\section{Da ciência para o esporte}

Um terceiro modelo ganha, paulatinamente, contornos mais explícitos e sua produção vai enfatizar a ciência para o esporte, dando a ver sutis transformações nas maneiras de representar as relações entre o movimento corporal, a ciência e a educação. Por um lado, permanecia a preocupação com a educação integral, com o tempo livre e as formas "saudáveis" de sua ocupação e com os valores morais de um mundo tomado por conflitos e debates sobre a ciência, a técnica, a política e os costumes. Por outro lado, a exaltação da técnica e da ciência em nome de um desenvolvimento tido como irrefreável e que seria capaz de conferir determinado status e legitimidade à Educação Física. Este novo modelo, que se afirma na década de 1970, foi constituído por múltiplas ações e interesses desenvolvidos tanto no próprio campo, quanto em âmbito estatal, a partir de políticas de fomento ao setor, realizadas principalmente pelo governo federal. Como marco importante dessas medidas efetivadas pelo governo militar, merece destaque a elaboração do Diagnóstico de EF/Desportos no Brasil, pelo Departamento de Educação Física e Desportos do Ministério da Educação e Cultura. Vale lembrar que um regime de governo autoritário se instaurou no Brasil em 1964, liderado por militares das forças armadas e apoiado por vários segmentos da sociedade civil. Dentre os principais traços dos governos militares daquele período estiveram o apelo nacionalista e o caráter "modernizadorconservador-autoritário" (MOTTA, 2014). 
Em seu texto de apresentação, o referido documento explicitava seu valor para a Educação Física nacional e as premissas sobre as quais as políticas para o setor deveriam ser constituídas:

O Diagnóstico coloca o País na posição privilegiada de poder, imediatamente, determinar uma política nacional para o setor, fundada em bases científicas e racionais, que permitirá, em prazo médio, desempenhar importante papel no aperfeiçoamento dos recursos humanos disponíveis no Brasil (DA COSTA, 1971, p. 8) $)^{5}$.

O apelo à ciência como condição fundante nas proposições do governo para Educação Física reflete o empenho realizado em várias frentes de trabalho, especialmente nos cursos superiores, onde estavam os sujeitos que buscavam pensar cientificamente a área. O contexto universitário tornou-se palco fundamental na realização de ações e projetos que intensificaram a constituição da Educação Física como disciplina acadêmica e como lugar de produção de conhecimento. Sobretudo nas instituições federais e especialmente após a Reforma Universitária de 1968, as ações caminharam no sentido de promover maior qualificação do seu corpo docente e de suas práticas junto à formação de professores na graduação. Assim, se investiu em cursos de especialização, na implantação de laboratórios de pesquisa, na criação de programas de pós-graduação e no estabelecimento de convênios internacionais de assistência técnico-científica com países como a Alemanha Ocidental e os Estados Unidos. Apostou-se também em novas estruturas e equipamentos, em divulgação científica, na publicação de periódicos e boletins de circulação nacional, na produção e na tradução de livros e outros materiais didáticos para formação de professores, além da expansão do número de cursos superiores em Educação Física.

Do ponto de vista das metodologias de ensino, uma organização didáticopedagógica de matriz comportamental passou a ser amplamente difundida, "em busca de uma tecnologia educacional" (TUBINO, 1980). Comumente reconhecida como educação tecnicista, enfatizava a organização e sistematização metódica para a produção de uma eficácia no ensino. Expressões como "planejar", "controlar" e "avaliar" ganharam uso frequente no campo semântico

5 Publicado em formato de livro em 1971, sob a coordenação de Lamartine Pereira da Costa, o Diagnóstico tinha como objetivo central verificar e relatar as condições da Educação Física e do Esporte em território nacional para a proposição de medidas administrativas, financeiras e estruturais que solucionassem os problemas desvelados pelo estudo. 
da formação de professores, não só na Educação Física (SANTOS, 2017; FARIA, 2019; SILVA, 2013), mas também nas demais licenciaturas. Ao priorizar os meios em detrimento dos fins, esse conjunto de procedimentos educacionais (e suas taxonomias) foi tratado como fator central para o êxito dos processos de ensino-aprendizagem.

Embora se possa dizer que as práticas concernidas ao âmbito universitário ganharam especial projeção na Educação Física daquele contexto, esse não foi o lugar exclusivo de investimento na/da área. A escola também foi alvo de alguns projetos e, as aulas de Educação Física, parte ativa no estabelecimento de um novo modelo para o campo. Proposições para o ensino dos antigos $1^{\circ} \mathrm{e}$ $2^{\circ}$ graus foram contempladas inclusive nos acordos de cooperação internacional estabelecidos pelo governo (TABORDA DE OLIVEIRA, 2009; SANTOS, 2017). No caso do convênio realizado com a Alemanha, um relatório foi sistematizado pela professora Liselott Diem (1983), coordenadora geral do projeto de cooperação e docente na Deutsche Sporthochschule Köln. Dentre as ações apresentadas no documento, há duas sessões destinadas às atividades propostas para a Primarbereich/Grundschule (área primária/escola primária) e a Sekundarbereich (área secundária).

O argumento apresentado por Diem (1983, p. 95) dá indícios sobre as práticas pedagógicas que, segundo a autora, deveriam frequentar a Educação Física escolar brasileira. A especialista alemã argumenta que era possível constatar uma divisão e sistematização "totalmente inadequadas" dos conteúdos das aulas, especialmente para os primeiros quatro anos escolares. Ressalta também que o termo "Rekreation" (recreação) era utilizado de modo geral para designar tais conteúdos. Como era de esperar, Diem apresenta como adequado o modo de organização do currículo alemão, que estabelecia "um programa coordenado para cada faixa etária e para cada ano letivo" e o emprego de uma metodologia que levava em consideração a aprendizagem progressiva e encadeada, do desempenho mais simples para o mais complexo, explicitando assim uma adesão à racionalidade moderna e cumulativa adotada para o ensinar e o aprender. Ademais, seu conjunto de argumentos indicia que o Schulsport (esporte escolar), como palavra-chave e como uma nova modelagem para a Educação Física, deveria orientar um plano de reforma, se contrapondo ao modo de organização que parecia vigente nas aulas. $\mathrm{O}$ esporte e sua racionalidade cientifica passavam a orientar as mudanças anunciadas para o ensino e para a formação docente. Na crítica à "recreação" e à realização de "jogos e exercícios de habilidade sem propósito específico", identificamos pistas que nos permitiram "descritivamente dar conta das rupturas e dos deslocamentos operados nas práticas" (CARVALHO, 2011, p. 191) e que alicerçaram analiticamente esse terceiro modelo pedagógico mapeado por nossos estudos. 
Tanto a Educação Física ensinada nas escolas, quanto a formação de seus professores, foram ainda impactadas por outro aspecto de relação direta com os acordos internacionais. Nesse sentido, a presença de especialistas, práticas, dispositivos didáticos e prescrições oriundos de países como a Alemanha e os Estados Unidos contribuíram significativamente para a implantação e assimilação, na Educação Física brasileira dos anos de 1970, das emergentes "Ciências do Esporte". Pode-se dizer que esses novos sistemas postos em relação foram "ganhando corpo, fazendo alma, adquirindo consciência e consistência", como anunciou, em 1981, o editorial da Revista Brasileira de Ciências do Esporte (RBCE, 1981, p. 4). Tal impresso foi concebido como meio de divulgação do conhecimento científico pelo Colégio Brasileiro de Ciências do Esporte, fundado em 1978. No mesmo editorial, foram apresentadas importantes considerações em torno da prática pedagógica dos professores:

O Colégio Brasileiro de Ciências do Esporte [...] tem procurado mostrar ao Brasil os novos rumos das Ciências do Esporte, ao modo como os grandes centros mundiais fazem há um bom tempo. [...]. O professor de Educação Física não pode mais ser representado como homem forte e de boa vontade que distrai os alunos entre aulas de biologia e matemática. [...]. Hoje, mais do que nunca, ele está envolvido no processo global de formação sociocultural do nosso jovem; hoje ele deve associar seu apito e seu cronômetro ao trabalho de laboratórios de fisiologia do exercício; hoje ele é o responsável pelo surgimento dos atletas e pelo desenvolvimento de suas potencialidades; em resumo, hoje ele não é mais o "professor de ginástica", mas o mestre em ciências do esporte (RBCE, 1981, p. 4, grifos no original).

Aqui, duas questões interdependentes chamam a atenção: a reivindicação tanto de uma condição cientifica, quanto esportiva para a Educação Física. A combinação desses dois sistemas parecia conduzir ao tom preciso que a Educação Física deveria atingir. Talvez por isso as Ciências do Esporte tenham sido bem assimiladas pelo campo, chegando, em alguns momentos, a ser o termo utilizado como sinônimo de Educação Física. Ao apostar na associação de elementos do "fazer pedagógico" - reduzidos ao apito e ao cronômetro - com aqueles relacionados à produção de um "saber" - laboratórios de fisiologia do exercício -, identificamos os deslocamentos nas representações sobre a Educação Física. Nesses termos, ao interrogar uma prática baseada em repertórios pedagógicos do "como fazer" e do "como educar", a Educação Física se afirmava por outras referências, orientadas pelo refinamento da inquirição, da pesquisa e da teoria, ou seja, por um novo estatuto científico. 
Com contornos muito claros, o modelo pedagógico que toma a ciência para o esporte como metáfora para a disciplina apostava em um formato de cientificidade que previa a mensuração do corpo humano (e de suas capacidades) de maneira cada vez mais detalhada - a partir de processos de experimentações e testagens matematizadas, laboratoriais -, e o estabelecimento de padrões universalmente aplicáveis, ou seja, uma prática científica protocolar. Além disso, deveria ser avalizado por uma comunidade internacional, considerada mais desenvolvida e especializada.

A centralidade que o fenômeno esportivo passa a ocupar no campo também constitui importante ênfase na Educação Física vivenciada nos anos do regime militar. Embora o esporte já estivesse presente nas escolas, a partir desse marco o professor tornava-se "responsável pelo surgimento dos atletas e pelo desenvolvimento de suas potencialidades" (RBCE, 1981, p. 4). O esporte a ser considerado seria aquele regido pelos códigos do alto nível, do rendimento, da competição e dos recordes. A escola foi eleita como um local privilegiado para a descoberta de talentos esportivos: um "celeiro de atletas". Nesses moldes, nota-se que relações foram estabelecidas entre o tempo da aula e as sessões de treinamento, o professor escolar e o técnico esportivo, o aluno e o potencial atleta. Para além da esportivização do próprio espaço da aula, as políticas impulsionaram investimentos em práticas extraescolares, que priorizavam competições esportivas, como por exemplo, os Jogos Estudantis Brasileiros (TABORDA DE OLIVEIRA, 2009; SANTOS, 2017). O estudo de Gabriela Arantes (2013) nos permitiu identificar que o novo modelo pedagógico eclipsou o esporte como "meio" no processo educativo, elevando-o ao lugar de "fim" nesse processo. Evidencia-se, assim, uma aposta contundente no sistema esportivo como dispositivo modelar para a Educação Física, o que o tornou conteúdo e temática hegemônica nas práticas pedagógicas e científicas da área.

As transformações operadas na Educação Física a partir do estabelecimento de um protocolo pedagógico, como o da ciência para o esporte, guardavam profunda relação com práticas já em voga na área. Nessa direção, não era mais satisfatório apenas dominar a execução de um movimento esportivo, ou a aplicação de uma técnica de arremesso, ou dizer que certa sequência nas aulas de Educação Física era mais eficiente do que outra. A partir da nova modelagem, era necessário a busca pela compreensão dos detalhes, pelo estudo e produção da teoria, pelo estabelecimento lógico das frequências e pela aplicabilidade na aprendizagem e no treinamento. Das práticas corporais, às práticas científicas. 


\section{Notas finais}

Como contribuições para os estudos que, em perspectiva histórica, analisam a Educação Física brasileira e a formação de seus professores, buscamos nesse trabalho refinar a operatividade da noção de modelo pedagógico, compreendendo-o como produção cultural. Nosso esforço se diferenciou de outras perspectivas analíticas que buscam enquadrar em etapas, tendências ou abordagens, as experiências dos sujeitos na cultura. Isso porque operamos com a premissa de que as práticas são desveladas pelos indícios de sua fabricação, uso e circulação, em determinado tempo e lugar. A partir do trabalho minucioso com as fontes, interessou-nos recolher e discernir os elementos constituintes de cada modelo, atentando para a sua inteligibilidade. Com o propósito de apresentar elementos-chave de um amplo programa de pesquisa, buscamos nesse artigo realçar e colocar em contraste a ortopedia do corpo, a eficiência dos gestos e a ciência para o esporte como formas disciplinares distintas de produção de sentidos para a Educação Física. Conforme nos ensina Carvalho (2011, p. 192), "analisar um objeto cultural implica considerá-lo um modelo, nele discernindo as marcas inscritas em sua configuração material, como dispositivo de modelização dos usos que prescreve". Não menos importante foi constatar que essas práticas de modelização não recusam a análise das maneiras como os sujeitos se apropriam delas. São múltiplas as possibilidades, os desvios, as bricolagens. Michel de Certeau adverte que "a presença e a circulação de uma representação [...] não indicam de modo algum o que ela é para seus usuários. É ainda necessário analisar a sua manipulação pelos praticantes que não a fabricam" (CERTEAU, 1998, p.40). Nesses termos, um convite para que os estudos continuem perscrutando as singularidades forjadas pelos fazeres dos professores, os deslocamentos e acomodações que produzem inventivamente, em cada tempo e lugar, a partir dos modelos que lhes são oferecidos. 


\section{REFERÊNCIAS}

ARANTES, Gabriela Villela. A Educação Física em cena: olhares sobre o Colégio Estadual de Minas Gerais (1956-1973). 2013. 170 f. Dissertação (Mestrado em Educação) - Faculdade de Educação, Universidade Federal de Minas Gerais, Belo Horizonte, 2013.

AVELAR, Ana Claudia. Uma ginástica que também se lê: a produção do Compendio de Gymnastica Escolar de Arthur Higgins (1896-1934). 2018. 180 f. Dissertação (Mestrado em Educação) - Faculdade de Educação, Universidade Federal de Minas Gerais, Belo Horizonte, 2018.

BAÍA, Anderson Cunha; MORENO, Andrea. Revista Brasileira de Educação Física: a Moderna Ginástica Sueca no Brasil (1944-1952). Cadernos de História da Educação, Uberlândia, v. 19, n. 3, p. 686-706, ago. 2020. DOI: https://doi.org/10.14393/chev19n3-2020-2.

CARVALHO, Marta Maria Chagas de. Pedagogia moderna, Pedagogia da Escola Nova e Modelo Escolar Paulista. In: CARVALHO, Marta Maria Chagas de; PINTASSILGO, Joaquim (org.). Modelos Culturais, Saberes Pedagógicos, Instituições Educacionais. São Paulo: Editora da USP/Fapesp, 2011. p. 185-212.

CARVALHO, Marta Maria Chagas de. A escola e a República e outros ensaios. Bragança Paulista: EDUSF, 2003.

CARVALHO, Marta Maria Chagas de. Quando a história da educação é a história da disciplina e da higienização das pessoas. In: FREITAS, Marcos Cezar (org.). História social da infância no Brasil. São Paulo: Cortez, 1997. p. 269-287.

CERTEAU, Michel de. A invenção do cotidiano: 1.artes de fazer. 3. ed. Petrópolis: Vozes, 1998.

CUNHA, Luciana Bicalho da. A Educação Física Desportiva Generalizada no Brasil: princípios e sistematizações de um método de ensino em circulação (1952-1980). 2017. 262 f. Tese (Doutorado em Educação) - Faculdade de Educação, Universidade Federal de Minas Gerais, Belo Horizonte, 2017.

DA COSTA, Lamartini P. Diagnóstico de Educação Física e Desportos no Brasil. Brasília: CDRH-MP, DEF, MEC, 1971.

DALBEN, André; DANAILOF, Kátia. Natureza urbana: parques infantis e escola ao ar livre em São Paulo (1930-1940). Revista Brasileira de Ciências do Esporte, Campinas, v. 31, n. 1, p. 163-177, set. 2009.

DIEM, Liselott. Sportförderung in Brasilien: Bericht über die Förderung des Sports in der Föderativen Republik Brasilien durch die Bundesrepublik Deutschland 1963 bis 1982. Alemanha: Verlag Hans Richarz-Sankt Augustin, 1983.

FARIA JÚNIOR, Alfredo Gomes. Introdução à Didática de Educação Física. 2. ed. Rio de Janeiro: Fórum, 1974. 
FARIA, Jacqueline Fidelis. "Um fator seguro de formação adequada": reformulação curricular na Escola de Educação Física (1974-1976). 2019. 124 f. Dissertação (Mestrado em Educação) - Faculdade de Educação, Universidade Federal de Minas Gerais, Belo Horizonte, 2019.

FONSECA, Ana Paula G. Formar (moralmente), instruir (o movimento), treinar (o gesto): Os Cursos de Educação Física por Correspondência e a Formação de Professores (19571969). 2020. 174 fls. Dissertação (Mestrado em Educação) - Faculdade de Educação, Universidade Federal de Minas Gerais, Belo Horizonte, 2020.

GONDRA, José. Artes de civilizar: Medicina, Higiene e Educação Escolar na Corte Imperial. Rio de Janeiro: EdUERJ, 2004.

JORNAL MINAS GERAES, p. 4, 9 set. 1926.

JORNAL MINAS GERAES, p. 9, 5 out. 1928.

JORNAL MINAS-GERAIS, p. 8, 29 e 30 jun. 1931.

LAURET, Paulo. Manual theorico-practico de gymnastica para uso dos lycéus, collegios, escolas municipaes e primarias. Lisboa: Empreza Horas Românticas, 1881.

LIMA, Cássia Danielle M. D. Ensino e formação: “os mais modernos conceitos e métodos" em circulação nas Jornadas Internacionais de Educação Física (Belo Horizonte, 1957-1962). 2012. 188 f. Dissertação (Mestrado em Educação) - Faculdade de Educação, Universidade Federal de Minas Gerais, Belo Horizonte, 2012.

LINHALES, Meily A. Tránsito de sujetos y métodos norteamericanos: propuestas para la enseñanza de la educación física dentro e fuera de las escuelas brasileñas. In: MOCTEZUMA, Lucia Matinez (coord.). Formando el cuerpo del ciudadano: aportes para una historia de la educación física en Latinoamérica. México: Universidad Autónoma del Estado de Morelos, 2015. p. 259-278.

LINHALES, Meily A; FONSECA, Ana Paula G. Paulo Lauret: um mestre português de ginástica na imprensa periódica do Rio de Janeiro (1880-1918). In: CONGRESSO LUSO BRASILEIRO DE HISTÓRIA DA EDUCAÇÃO, 11., Porto, 2016. Acta [...]. Porto: CITCEM, 2016. p. 707-718.

LOPES, Eliane Marta Teixeira. Métodos e fontes na história da Educação e Educação Física. In: ENCONTRO NACIONAL DE HISTÓRIA DO ESPORTE, LAZER E EDUCAÇÃO FÍSICA, 4., 1996, Belo Horizonte. Anais [...]. Belo Horizonte: CHELEF, 1996. p. 35-49.

MOTTA, Rodrigo Patto Sá. As universidades e ditadura militar: cultura política brasileira e modernização autoritária. Rio de Janeiro: Zahar, 2014.

PUCHTA, Diogo Rodrigues. A escolarização dos exercícios físicos e os manuais de ginástica no processo de constituição da educação física como disciplina escolar (1882-1926). 2015. 286 f. Tese (Doutorado em Educação) - Faculdade de Educação, Universidade Federal de Minas Gerais, Belo Horizonte, 2015. 
PUCHTA, Diogo Rodrigues; TABORDA DE OLIVEIRA, Marcus Aurélio. Tempos e espaços de ginástica: sentidos e sensibilidades que se educam. Revista Movimento, Porto Alegre, v. 25, p. 1-16, 2019. DOI: https://doi.org/10.22456/1982-8918.90303.

QUITZAU, Evelise Amgarten; MORAES E SILVA, Marcelo. Educación Física y ciencia: una mirada historiográfica. Revista da ALESDE, Curitiba v. 12, n. 01, p. 23-42, jun. 2020.

RBCE. Editorial. Revista Brasileira de Ciências do Esporte, São Caetano do Sul, v. 2, n. 2, p. 4, 1981.

ROMÃO, Anna Luiza Ferreira. Entre Escolas, Clubs e Sociedades: as Gymnasticas tecidas por professores no Rio de Janeiro (1850-1900). 2016. 199 f. Dissertação (Mestrado em Educação) - Faculdade de Educação, Universidade Federal de Minas Gerais, Belo Horizonte, 2016.

SANTOS, Fernanda Cristina. Bola em jogo entre Brasil e República Federal da Alemanha: cientificidade e modelagem pedagógica na formação de professores na Escola de Educação Física da UFMG (1963-1982). 2017. 193 f. Dissertação (Mestrado em Educação) - Faculdade de Educação, UFMG. Belo Horizonte, 2017.

SCHNEIDER, Omar. Entre a correção e a eficiência: mutações no significado da educação física nas décadas de 1930 e 1940: um estudo a partir da Revista Educação Physica. Revista Brasileira de Ciências do Esporte, Campinas, v. 25, n. 2, p. 39-54, jan. 2004.

SCHREBER, Daniel Gottlieb Moritz. Gymnastica doméstica, médica e hygiênica ou representação e descrição de movimentos gymnasticos. Lisboa: Candido Magalhães, [18--?].

SILVA, Giovanna Camila. A Associação Cristã de Moços e experiências de escolarização da Educação Física no Brasil: sujeitos, ideias e práticas acemistas em circulação. 2017. 236 f. Tese (Doutorado em Educação) - Faculdade de Educação da UFMG, Belo Horizonte, 2017.

SILVA, Giovanna Camila. Entre playgrounds, praças de jogos e jardins de recreio: o debate sobre a proveitosa ocupação do tempo. Revista Movimento, Porto Alegre, v. 25, p. 1-12, 2019. DOI: https://doi.org/10.22456/1982-8918.92967.

SILVA, Gustavo da M. A Escola de Educação Física e Desportos da UFRJ no Período do Governo militar (1968-1979): o curso de formação de professores e sua "invenção". 2013. 161 f. Dissertação (Mestrado em Educação) - Faculdade de Educação, Universidade Federal do Rio de Janeiro. Rio de Janeiro, 2013.

TABORDA DE OLIVEIRA, Marcus Aurélio. O esporte brasileiro em tempos de exceção: sob a égide da ditadura (1964-1985). In: DEL PRIORE, Mary; MELO, Victor Andrade de (org.). História do esporte no Brasil: do Império aos tempos atuais. São Paulo: Editora UNESP, 2009. p. 387-416.

TUBINO, Manoel José Gomes. Em busca de uma tecnologia educacional para as Escolas de Educação Física. São Paulo: IBRASA, 1980. 
VAGO, Tarcísio Mauro. Histórias de Educação Física na escola. Belo Horizonte: Mazza, 2010.

VIDAL, Diana Gonçalves; PAUlilo, André Luiz. Projetos e estratégias de implementação da escola nova na capital do Brasil (1922-1935). In: MAGALDI, Ana Maria; ALVES, Cláudia; GONDRA, José Gonçalves (org.). Educação no Brasil: história, cultura e política. Bragança Paulista: Editora Universidade São Francisco, 2003. p. 375-398.

XAVIER, Maria do Carmo. A tradição (re)visitada - A experiência do Centro Regional de Pesquisa Educacionais de Minas Gerais - CRPEMG (1956/1966). 2007. 213 f. Tese (Doutorado em Educação) - Faculdade de Educação, Universidade Federal de Minas Gerais, Belo Horizonte, 2007.

Texto recebido em $02 / 10 / 2020$.

Texto aprovado em 27/01/2021. 